\title{
Haplotype diversity of VVTFL1A gene and association with cluster traits in grapevine (V. vinifera)
}

Lucie Fernandez ${ }^{1,7^{*}}$, Loïc Le Cunff², Javier Tello ${ }^{1}$, Thierry Lacombe ${ }^{4,6}$, Jean Michel Boursiquot ${ }^{4}$, Alexandre Fournier-Level ${ }^{3}$, Gema Bravo ${ }^{5}$, Sandrine Lalet ${ }^{6}$, Laurent Torregrosa ${ }^{4}$, Patrice This ${ }^{4}$ and José Miguel Martinez-Zapater ${ }^{1,5}$

\begin{abstract}
Background: Interaction between TERMINAL FLOWER 1 (TFL1) and LEAFY (LFY) seem to determine the inflorescence architecture in Arabidopsis. In a parallel way, overexpression of VVTFL1A, a grapevine TFL1 homolog, causes delayed flowering and production of a ramose cluster in the reiterated reproductive meristem (RRM) somatic variant of cultivar Carignan. To analyze the possible contribution of this gene to cluster phenotypic variation in a diversity panel of cultivated grapevine (Vitis vinifera L. subsp. vinifera) its nucleotide diversity was characterized and association analyses among detected sequence polymorphisms and phenology and cluster traits was carried out.

Results: A total of $3.6 \mathrm{~kb}$ of the VVTFL1A gene, including its promoter, was sequenced in a core collection of 140 individuals designed to maximize phenotypic variation at agronomical relevant traits. Nucleotide variation for VVTFLIA within this collection was higher in the promoter and intron sequences than in the exon regions; where few polymorphisms were located in agreement with a high conservation of coding sequence. Characterization of the VVTFL1A haplotype network identified three major haplogroups, consistent with the geographic origins and the use of the cultivars that could correspond to three major ancestral alleles or evolutionary branches, based on the existence of mutations in linkage disequilibrium. Genetic association studies with cluster traits revealed the presence of major INDEL polymorphisms, explaining 16\%, 13\% and 25\% of flowering time, cluster width and berry weight, respectively, and also structuring the three haplogroups.
\end{abstract}

Conclusions: At least three major VVTFL1A haplogroups are present in cultivated grapevines, which are defined by the presence of three main polymorphism LD blocks and associated to characteristic phenotypic values for flowering time, cluster width and berry size. Phenotypic differences between haplogroups are consistent with differences observed between Eastern and Western grapevine cultivars and could result from the use of different genetic pools in the domestication process as well as different selection pressures on the development of table and wine cultivars, respectively. Altogether, these results are coherent with previous classifications of grapevine phenotypic diversity mainly based on cluster and berry morphotypes as well as with recent results on the structure of genetic diversity in cultivated grapevine.

Keywords: Plant reproductive development, Inflorescence structure, Flowering time, Berry size, Grape domestication, Grapevine

\footnotetext{
* Correspondence: Ifernandez@bordeaux.inra.fr

${ }^{1}$ Instituto de Ciencias de la Vid y del Vino (ICW), (CSIC, Universidad de La

Rioja, Gobierno de La Rioja), CCT, C/Madre de Dios 51, Logroño 26006, Spain

${ }^{7}$ current address: INRA, UMR Biologie du Fruit et Pathologie, B.P. 81,

Villenave-d'Ornon, Cedex 33883, France

Full list of author information is available at the end of the article
} 


\section{Background}

Grapevine (Vitis vinifera subsp. vinifera) was domesticated in the Neolithic period (ca. 8500-4000 BC) [1] from wild populations of Vitis vinifera subsp. sylvestris [2]. Archaeological data traced back the location of the earliest evidence for large-scale winemaking, likely linked to the use of domesticated plants, to the north of Zagros Mountains and in the Caucasian region [3] around 6000-5000 BC which supports that geographic area as the location for primo domestication events. From there, grapevine cuttings were widely spread: first from North to South; and later from East to West around the Mediterranean basin pathway [3]. Vegetative propagation and dissemination, spontaneous events of hybridization among cultivars, breeding with local wild plants and likely secondary domestication events generated the pattern of admixture that is observed in current cultivars [4-9]. The use of different genetic pools along the process of grapevine domestication and human selection for different uses such as fresh consumption, raisin or wine production have resulted in large variation for cluster size, compactness and architecture among cultivars from different geographic locations [10].

The size and shape of grapevine clusters is determined by the development and growth of inflorescences as well as the efficiency of pollination, fruit set and berry growth. Generally, wine grape cultivars present small (150-250 g) and compact clusters with small berries, while table grapes generally have large (300-400 g) and less compact clusters with large berries. Some of them can even be extremely big weighting up to $1000-1500 \mathrm{~g}$ [11]. Negrul [12] distinguished different grape morphotypes based in part on cluster and berry traits. Cluster architecture has implications on disease susceptibility, since cultivars with compact clusters are more susceptible to rot by Botrytis cinerea than those of loose clusters $[10,13,14]$. In spite of the relevance of cluster structure and compactness, very little is known about its genetic control probably due in part to the complexity of the trait, which depends on many different variables along the growth of the plant as well as the environmental interactions during its reproductive development. There is a need to define cluster shape and size in terms of quantitative variables to understand its genetic determination. So far, only a few studies have tried to identify the main variables responsible for variation in bunch compactness in grapevine. In this sense, Vail and Marois [14] identified cluster weight as the main factor to explain its variation while Shavrukov et al. [15] proposed total cluster length and node number per rachis as two of the main ones. Recently, Tello and Ibañez [16] evaluated 19 indexes to estimate cluster compactness highlighting the role of various cluster parameters such as branch length and number. The study proposed a fast and good estimator for cluster compactness based on cluster weight and length.

Genetic and molecular analyses in model plants, such as Arabidopsis thaliana, demonstrated the interaction between TERMINAL FLOWER 1 (TFL1) and LEAFY $(L F Y)[17,18]$ in the establishment of inflorescence architecture. Their interactions supported a simple model explaining the evolution of plants inflorescence architecture [19]. TFL1 belongs to a small gene family first identified in mammals as encoding phosphatidyl ethanolamine-binding proteins (PEBP) [20], which participates in a wide variety of biological functions in eukaryotes. In Arabidopsis, TFL1 has been shown to function in the transcriptional repression of flower meristem identity genes [21]. $L F Y$ encodes a plant specific transcription factor [22], which serves as a flower meristem identity regulator activating the transcription of other flower meristem identity genes [23]. Recently, the existence of a common genetic pathway controlling inflorescence architecture in Arabidopsis and rice has been demonstrated indicating that this pathway could be highly conserved in angiosperms [24]. Following this report, four MADS-box genes are required to suppress TFL1 in emerging floral meristems; what seems to be indispensable to initiate their differentiation.

In grapevine, the family of PEBP encoding genes includes at least five genes; three of them have deduced protein sequences related to Arabidopsis TFL1, being VvTFL1A the closest homologous sequence [25]. In fact, over-expression of $V v T F L 1 A$ in transgenic Arabidopsis plants generates phenotypes of large and late flowering inflorescences reminding those observed when overexpressing the endogenous Arabidopsis gene [25]. Likewise, recent findings show that the extreme cluster proliferation and delayed anthesis observed in the reiterated reproductive meristems (RRM) somatic variant of grapevine cultivar Carignan was caused by a single dominant mutation in the VvTFL1A gene. This dominant mutation was identified as the insertion of a class II transposable element, Hatvine1-rrm, in the VvTFL1A promoter, triggering up-regulation of the corresponding VvTFL1A allele in reproductive and vegetative organs of the shoot apex [26]. These results suggested a role for $V v T F L 1 A$ in the determination of inflorescence structure as well as on the branching pattern of the grapevine fruit clusters and the time of anthesis.

To further analyze the contribution of VvTFL1A to the phenotypic variation observed for reproductive and inflorescence traits in grapevine, the nucleotide diversity shown by this gene in a core collection of grapevine accessions was analysed and a candidate gene association approach on the variation observed for fertility index, phenological variables as well as several inflorescence and berry related traits was carried out. Herein the 
identification of VvTFL1A sequence polymorphisms associated with flowering and cluster traits is reported, being the most relevant ones corresponding to several INDELs in two intron regions. These INDELs are in LD with additional SNPs defining three LD blocks, which correspond to three major haplogroups. Interestingly, these haplogroups are characteristic of either wine or table cultivars in agreement with the cluster and flowering phenotype to which they are associated to.

\section{Methods}

\section{Plant material}

The plant material consisted of 140 grapevine cultivars corresponding to a core collection of Vitis vinifera L. subsp. vinifera intended to maximize agro-morphological diversity for 50 qualitative and quantitative traits [27]. All the cultivars are maintained at the INRA experimental station of Domaine de Vassal, Marseillan-plage, France (http://www1.montpellier.inra.fr/vassal/). The list of cultivars, pedigree when available, classification according to use (wine, table or wine/table), geographical group according to Bacilieri et al. [6], Lacombe et al. [28] and available data of the Vitis International Variety Catalogue (http:// www.vivc.de/) are shown in Additional file 1. Classification according to Eastern and Western origin was obtained considering cultivars from the Iberian Peninsula (IBER), Western and Central Europe (WCEUR) and the Italian Peninsula (ITAP) as occidental cultivars; whereas cultivars from the Balkans (BALK), Russia and Ukraine (RUUK), Eastern Mediterranean and Caucasus (EMCA), Middle and Far East (MFEAS) were considered as oriental cultivars. For newly bred grape varieties, their pedigree was used to assess Western or Eastern origin to classify them according to their genetic origin and not according to breeding location. When genetic origin of pedigree was questionable, the cultivar was considered to present mixed origin.

\section{Phenotypic evaluation}

Ten morphological traits related to the reproductive biology of grapevine were considered in this study. Among them, four were related to phenology (budburst time, flowering time, veraison time and maturity time); one to yield (fertility index); and five to berry and cluster features (berry weight and cluster length, width, weight and compactness). Cluster compactness was estimated from available data such as [cluster weight/(cluster length $)^{2}$ ] [16]. Principal component analysis separated on axis 2 phenological traits from cluster size traits being fertility index opposite to all other traits on axis 1 (Additional file 2). Strongest correlations were found between maturity and veraison time (Pearson's $r=0.82$ ) as well as between cluster weight and width (Pearson's $r=$ 0.80). All traits were scored at the Domaine de Vassal and were expressed as the mean value for five plants per accession analysed a maximum of three years following the recommended OIV descriptors as shown in Table 1 [11]. Details of phenotypic values obtained for each cultivar are given in Additional file 3. The phenotype distribution for these traits within the core collection is provided in Additional file 4.

\section{Genotyping}

For each genotype, $3.6 \mathrm{~kb}$ of the VvTFL1A gene (GSVIVT01036145001, chr6_20199669-20203319, Genoscope $12 \mathrm{X}$ ) were amplified and sequenced using primers listed in Fernandez et al. [26]. DNA was extracted from young leaves of each genotype as described in AdamBlondon et al. [29]. Amplifications were carried out using Taq DNA Polymerase (Qiagen) as recommended by manufacturer. PCR products were treated with Exosap-IT reagent as recommended by manufacturer and sequenced at the Genomic Service of the Parque Cientifico de Madrid in an ABI prism 3730 (Applied Biosystems) DNA sequencer. Base calling, quality trimming and alignment of $\mathrm{ABI}$ chromatograms was performed using SeqScape v2.5 (Applied Biosystems). Sequence polymorphisms were manually verified to establish genotypes. The nomenclature system used to name polymorphisms corresponded to letters followed by numbers: single letter correspond to the involved nucleotide substitution using the IUB's conventional nomenclature and "Ins" is used to designed INDEL; positive or negative numbers corresponded to polymorphism position from the first base of the "ATG start codon". Linkage disequilibrium (LD) calculations between polymorphisms were carried out using the LD option implemented in TASSEL v.2.1 [30].

Molecular diversity parameter estimates were calculated using DnaSP v4.50.2 [31]. Per site nucleotide diversity $(\pi)$ [32], Watterson $\theta$ estimate [33] and Tajima's D [34] were calculated for the whole haplotype set and separately for the three structured sub-populations (K1, $\mathrm{K} 2, \mathrm{~K} 3$ ).

\section{Association tests}

Knowing that population structure can bias association studies, the structured association (SA) method [35] and the Mixed Linear Model MLM [36] were used to reduce false positives. Population structure of the core collection was determined using 20 SSR markers well scattered throughout the 19 grape linkage groups (LGs) [37] by a Bayesian clustering implemented in STRUCTURE v.2.3.4 [38]. The ADMIXTURE model was applied assuming that segregation of alleles was independent. A burn-in period of 100,000 followed by 150,000 Markov Chain Monte Carlo (MCMC) iterations with 5 replicate runs were carried out for each value of population 
Table 1 List of traits analysed

\begin{tabular}{|c|c|c|c|}
\hline Trait & OIV code & Description & Units \\
\hline Budburst time & 301 & Mean budburst time compared with Chasselas cultivar of reference & Days \\
\hline Flowering time & 302 & Mean flowering time (50\% of open flowers) compared with Chasselas cultivar of reference & Days \\
\hline Veraison time & 303 & Mean veraison time (50\% of turn berries) compared with Chasselas cultivar of reference & Weeks \\
\hline Maturity time & 304 & Mean maturity time compared with Chasselas cultivar of reference & Weeks \\
\hline Yield $=$ Fertility index & 153 & (Number of inflorescence / number of shoot ) per plant & Count \\
\hline Berry weight & 503 & Average berry weight at maturity $\left(20^{\circ} \mathrm{Brix}\right)$ & Gram \\
\hline Cluster length & 202 & Average maximum cluster length at maturity $\left(20^{\circ} \mathrm{Brix}\right)$ & Centimeter \\
\hline Cluster width & 203 & Average maximum cluster width at maturity ( $\left.20^{\circ} \mathrm{Brix}\right)$ & Centimeter \\
\hline Cluster weight & 502 & Average cluster weight at maturity ( $\left.20^{\circ} \mathrm{Brix}\right)$ & Gram \\
\hline Cluster compactness & & Cluster weight/(cluster length) $)^{2}$ & $\mathrm{Gram} / \mathrm{cm}^{2}$ \\
\hline
\end{tabular}

structure tested $(1 \leq \mathrm{K} \leq 10)$. The optimal sub-population model was selected with the maximal likelihood $K=3$ according to the $\Delta K$ method [39] and later corrections for $\Delta K$ artefacts [40]. The corresponding Q-matrix was used for structured association tests. An arbitrary cut-off value of $50 \%$ ancestry was set to assign each individual to one of the three sub-population clusters (Additional file 1). Individuals not assigned in one sub-population were considered as admixed. This structure discriminates cultivars according to their use and geographic origin with $\mathrm{K} 2$ mainly constituted by western wine cultivars (78\%), K3 by eastern table cultivars (78\%) and K1 composed by eastern and western wine cultivars and table cultivars (Figure 1). The kinship matrix was calculated on the basis of the same set of SSR markers [41] using TASSEL v.2.1.

Comparison of the naïve General Linear Model (GLM) test, the structured association test (GLM-Q) and the structured Mixed Linear Model (MLM-Q) using TASSEL v.3 identified the last one as the most conservative model and was therefore selected to perform the association tests. MLM-Q association tests were carried out using the $R$ v.2.15 [42] and TASSEL v.3 software.
Polymorphic sites carrying rare alleles (frequencies $<5 \%$ within the total sample) and unbalanced genotypic classes (frequencies $<5 \%$ within the total sample) were discarded to avoid biased associations. Rare genotypic classes were in this last case replaced by missing data. Polymorphisms were codified to test both additive and dominant effects using $\mathrm{R}$ to be similar with marker model tested using TASSEL. For traits showing significant associations after Bonferroni correction $(P \leq 0.05)$ using either TASSEL or $\mathrm{R}$, multi-locus mixed-models using forward-backward stepwise regression (MLMM) were implemented using the $\mathrm{R}$ software to identify major non-redundant associated markers [43]. Population structure and kinship were both included in the multilocus analysis. Best models were selected according to the extended Bayesian information criteria (EBIC) and the multiple Bonferroni criteria (mBonf) according to Segura et al. [43].

\section{Haplotype reconstruction and networks}

As $V$. vinifera genotypes are generally highly heterozygous [37], the unphased genotypic dataset was analysed to identify the succession of linked polymorphisms along
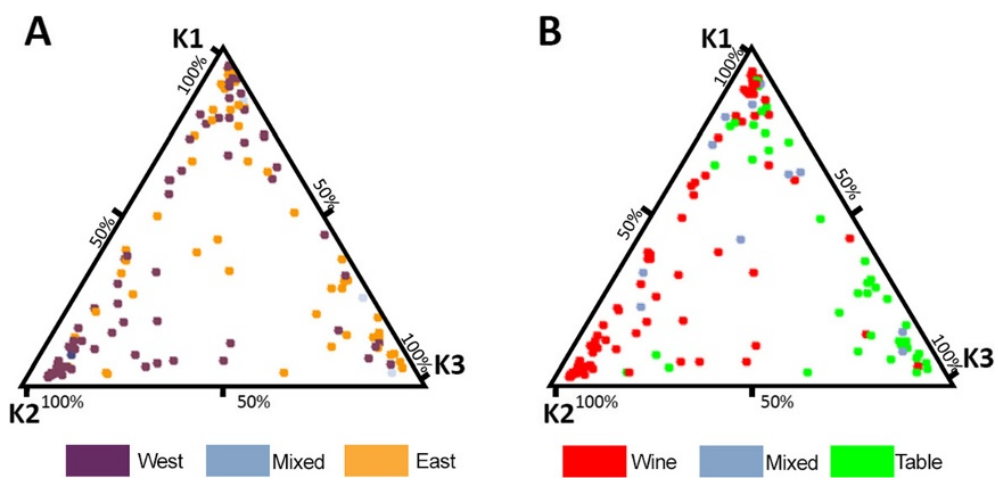

Figure 1 Population structure of the V.vinifera core collection. Schematic representation of estimated membership was obtained using STRUCTURE and classification of the individuals to one of the three genetic groups (K1, K2 and K3) was obtained using 50\% of ancestry. Geographic origin (A) and fruit use (B) of each cultivar are indicated using colour codes. 
the sequenced DNA region. Haplotypes were reconstructed using a PLEM algorithm [44] implemented in PHASE v2.1 applying default values of the iterative scheme [45]. Reconstructed haplotypes were submitted separately and simultaneously to three recombination detection tests implemented in the Recombination Detection Program v3beta41 [46]. Those were the MaxChi method with a window size of $12,20,25$ or 30 variables sites [47], the Chimaera method with a window size of $12,20,25$ or 30 variables sites [48] and the 3SEQ method [49]. To ensure consistency, haplotypes showing a significant probability of being the result of recombination $(P \leq 0.05)$ in at least two tests were considered as recombinants and excluded from further analysis as previously done by Fournier-Level et al. [50].

Network analysis was carried out using the medianjoining method [51] implemented in Network v4.5.1.6 (Fluxus Technology, Sudbury, UK) and fixing a weight of 99 for the polymorphisms showing best associations with traits (Ins883, Ins422, K-737 and M-196). Three haplogroups HGA, HGB and HGC were defined according to the three LD blocks.

\section{Results}

VvTFL1A structure and sequence polymorphisms

A total of $3646 \mathrm{bp}$ of the VvTFL1A gene corresponding to $2442 \mathrm{bp}$ and $1204 \mathrm{bp}$ before and after ATG, respectively, were sequenced in all the individuals of the core collection. Translation of coding sequences identified the annotated four exons in the $V$. vinifera PN40024 genome sequence [52] of 201, 62, 41 and 218 bp and three introns of 83, 467 and 107 bp (Figure 2A). Nucleotide sequence analyses enabled the identification of 70 polymorphisms (64 SNP and 6 INDEL including 3 microsatellites). Among them, 44 polymorphisms were located in the promoter sequence, 4 in the 5 ' untranslated

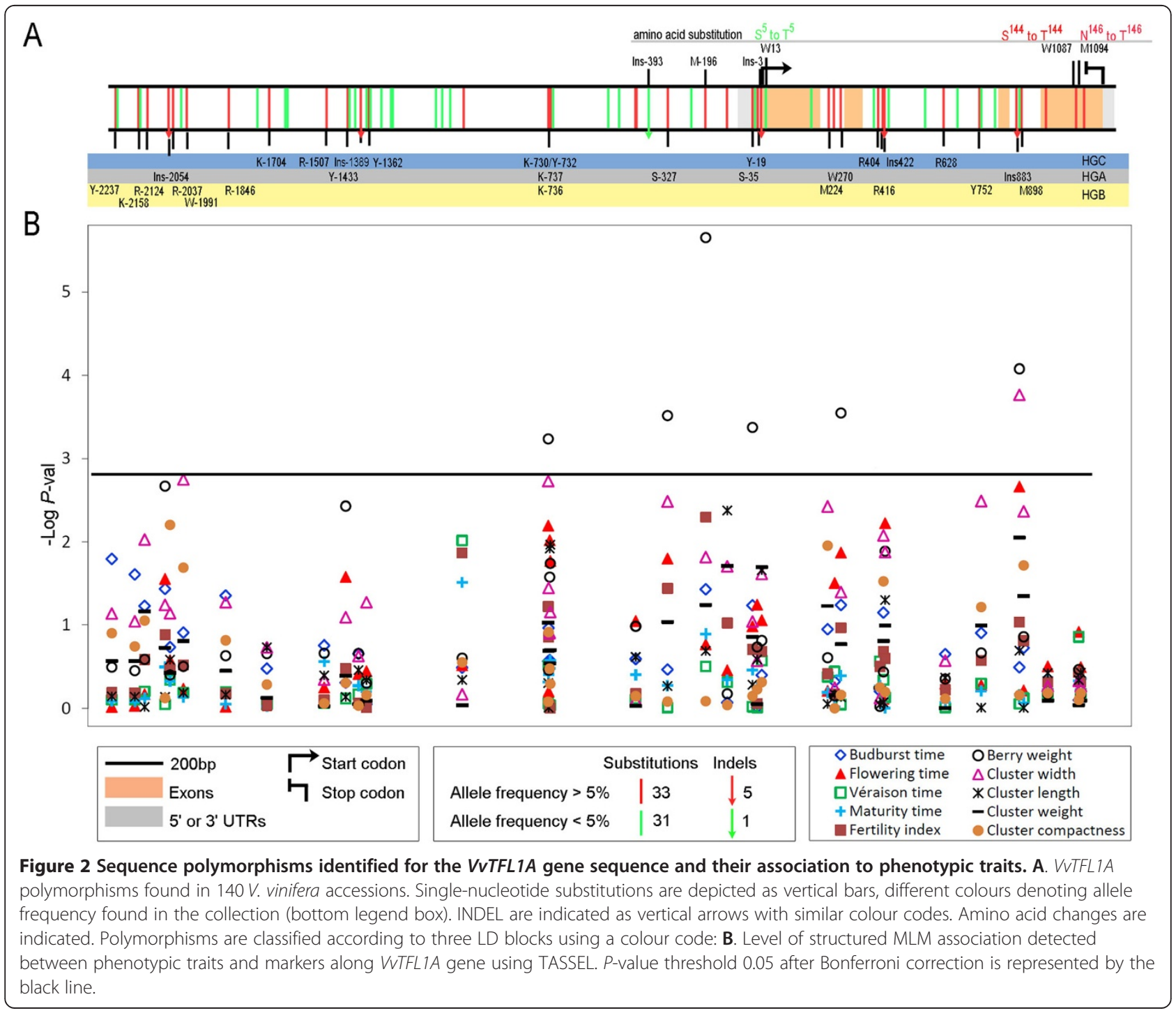


region, and 5 and 17 polymorphisms were located in exonic and intronic regions, respectively. INDEL Ins-2054 and Ins-1389, located in the promoter, and Ins883 in intron 3, involved 5, 21 and 1 nucleotides, respectively; whereas Ins-393 and Ins-3 in the promoter, and Ins422 in intron 2 represented microsatellite variations with Ins422 being biallelic and the other two multiallelic (Figure 2A). Out of the five exonic SNP, only three (W13, W1087, and M1094) caused non-synonymous amino acid substitutions and are shown in Figure 2A. Among the 70 polymorphisms, $32(46 \%)$ were represented by a rare allele (frequency $<5 \%$ ), with 10 of them grouped between position -1079 and -1430 before ATG. The complete genotypic data set is available in Additional file 5.

\section{VVTFL1A nucleotide diversity}

A total of 62 haplotypes, including 37 singletons, were identified based on phase reconstruction using the 70 segregating polymorphisms (Additional file 6). Genetic diversity of $V v T F L 1 A$ gene was estimated in terms of number of segregating sites $(S)$ and polymorphism ( $\pi$ and $\theta$ ) for all the haplotypes and according to population structure. Comparison of genetic diversity index among the 3 genetic groups inferred within the analysed core collection (see Material and Methods) indicated that despite K3 sub-population included a smaller number of haplotypes than the two other K1 and K2 sub-populations; this presented a high number of segregating sites and $\pi$ and $\theta$ polymorphism indexes (Table 2). The Tajima's $D$-tests showed a general neutral value considering all haplotypes and a slight but nonsignificant negative value in K1 sub-population compared with $\mathrm{K} 2$ sub-population, which showed a slight positive value (Table 2 ). When Tajima's $D$-test was estimated in sliding windows along $V v T F L 1 A$; the test revealed a similar pattern of variation for $\mathrm{K} 1$ and $\mathrm{K} 3$ sub-populations with a general negative value along $V v T F L 1 A$ promoter (Figure 3 ). In contrast, the value of $D$ along the transcribed region in K3 sub-population increased to reach a positive value. In K2 sub-population, Tajima's $D$-test showed general positive value in both promoter and transcribed regions. These patterns indicated different selection or demographic events between haplotypes within the three genetic groups.

\section{Table 2 Pattern of diversity and neutrality tests for} VvTFL1A gene

\begin{tabular}{lllll}
\hline & All Haplotypes & K1 & K2 & K3 \\
\hline $\mathrm{S}$ & 70 & 62 & 50 & 48 \\
$\mathrm{H}$ & 62 & 37 & 35 & 16 \\
$\pi$ & 0.00401 & 0.00365 & 0.00418 & 0.00412 \\
$\theta$ & 0.00439 & 0.00439 & 0.00348 & 0.00442 \\
D $_{\text {Tajima }}$ & -0.29978 & -0.61965 & 0.72764 & -0.29739 \\
\hline
\end{tabular}

$\mathrm{S}$ indicates number of segregating sites and $\mathrm{H}$ haplotype number. Analysis has been carried out in the three clusters of individuals related to the population structure. All tests yielded non-significant $P$-values $(P>0.05)$.

\section{VVTFL1A haplotypes}

In order to study relationship between $V v T F L 1 A$ haplotypes, those likely resulting from recombinant events were detected to avoid bias. Among the 62 haplotypes originally identified, 26 were considered recombinants (Additional file 6) and were removed for haplotype network analysis. Haplotype network was constructed using 36 non-recombinant haplotypes that included 19 singletons. Haplotype network discriminated three groups of closely related haplotypes or haplogroups (HGA, HGB and $\mathrm{HGC}$ ), which were clearly structured in relation with mutations in linkage disequilibrium (LD) (Figure 4). Within HGA major part of the haplotypes (44\%) were present in cultivars of the $\mathrm{K} 1$ sub-population including Eastern and Western cultivars used as table and wine grapes. The remaining haplotypes of HGA were similarly found in cultivars of the K2 and K3 sub-population (25\% and $24 \%$, respectively). Regarding $\mathrm{HGB}$ and HGC 52\% and $68 \%$ of their haplotypes were detected in cultivars of the K2 sub-population mainly represented by Western wine cultivars (Figure 4).

Haplotypes 32 and 3 were the most frequent (frequency $>0.15$ on the total haplotype pool and $>0.19$ when excluding the recombinants) and belonged to HGA and $\mathrm{HGB}$, respectively. Most of the cultivars of the core collection were heterozygous for two different haplotypes (86\%) with $20 \%$ of them being heterozygous for a combination of HGA and HGB haplotypes (Additional file 1). Only 20 cultivars were homozygous (14\%) with eight and five varieties homozygous for HGA and HGB haplotypes, respectively. Two cultivars were homozygous for haplotype 54 of HGC and the remaining homozygous accessions presented putative recombinant haplotypes.

Regarding the recombinant haplotypes, haplotype 18, which was the most frequent (frequency $=0.05$ ), corresponded to a recombination between haplotypes from HGA and HGB (Additional file 6). Indeed, no allele specifically assigned to HGC was present in this haplotype, which was always combined with alleles typical of both HGA and HGB haplotypes. Interestingly; haplotype 18 was present only in cultivars of K1 (40\%) and K3 (60\%) sub-populations classified mainly as Eastern table grapes, with two cultivars being homozygous for this haplotype (Additional file 1). Furthermore, among the individuals that presented at least one HGC haplotype mainly composed by cultivars of the $\mathrm{K} 2$ sub-population, the only one Eastern table cultivar belonging to the K3 subpopulation was a combination with haplotype 18 .

Certainly, LD pattern along VvTFL1A gene revealed three main blocks of linked polymorphisms (Figure 5): linked polymorphisms specific of HGA (Ins-2054, Y1433, K-737, S-327, S-35, W270, Ins883) located in the promoter, the first and the third introns of $V v T F L 1 A$ gene; linked polymorphisms specific of HGB (Y-2237, K- 


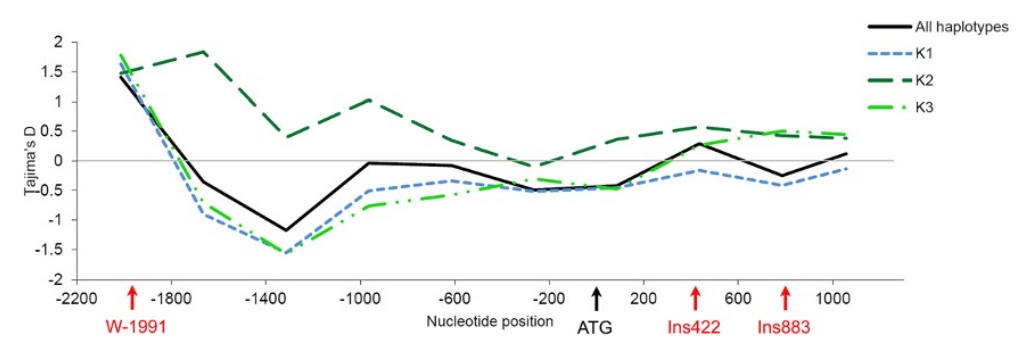

Figure 3 Pattern of Tajima's D values along VvTFL1A gene. Neutral selection $(D=0)$ is represented by the grey line. Patterns have been obtained using sliding windows option from DnaSP ( window length $=500$ and step size $=350$ ).

2158, R-2124, R-2037, W-1991, R-1846, K-736, M224, R416, Y752 and M898) identified in the distal promoter region and in the three intron regions; and linked polymorphisms specific of HGC (K-1704, R-1507, Ins-1389, Y-1362, Y-732, K-730, Y-19, R404, Ins422, R628) located in the promoter and the second intron of the $V v T F L 1 A$ gene. Thus, haplogroups HGA, HGB, and HGC are consistent with the existence of three ancestral alleles or evolutionary branches supported by polymorphisms in the three LD blocks.

\section{Candidate gene association}

Considering the biological function established for the Arabidopsis TFL1 gene as well as the phenological traits altered in the Carignan RRM somatic variant, the candidate gene association study was focused on those

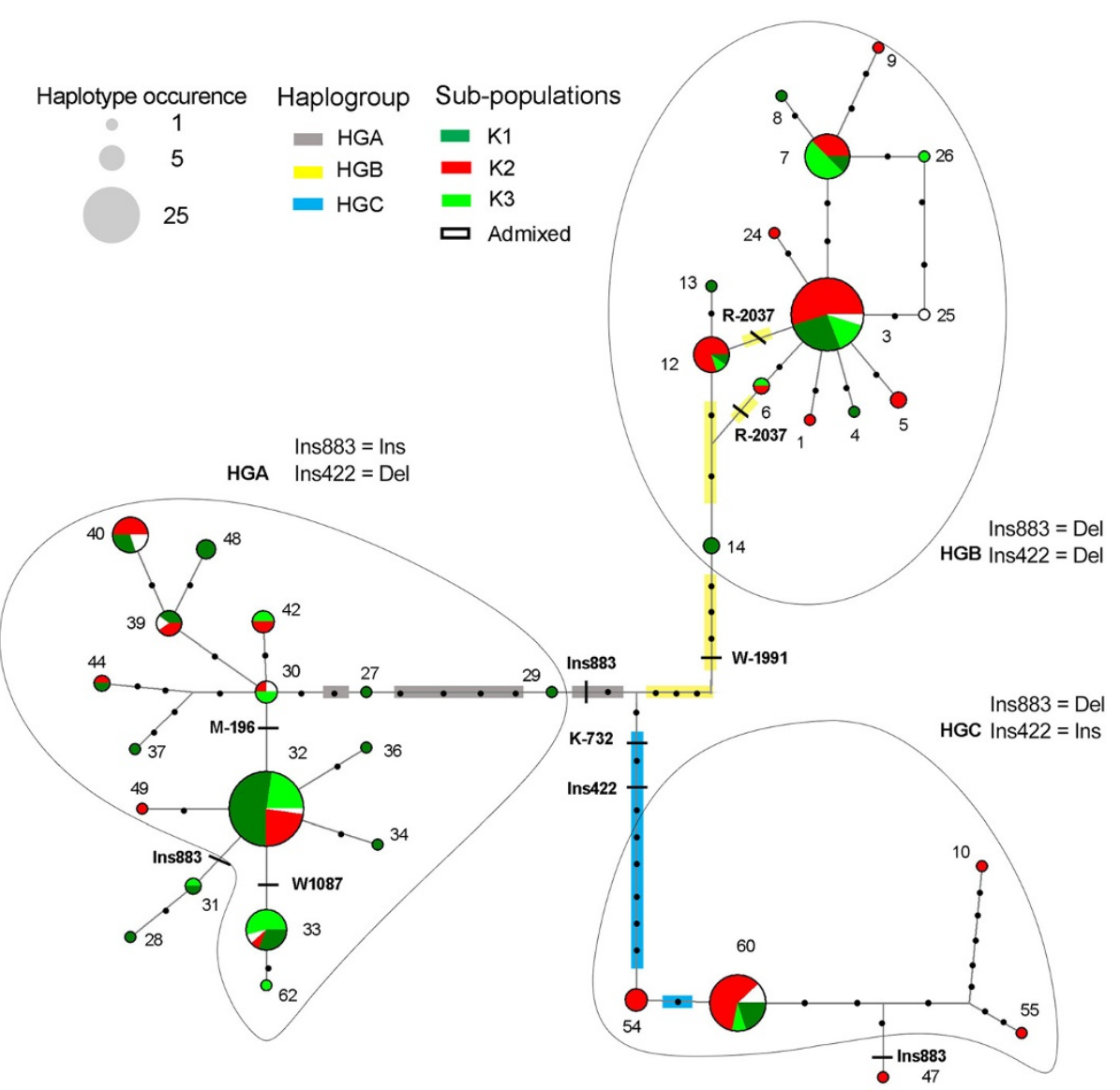

Figure 4 Median joining networks derived from reconstructed DNA sequence haplotypes of VvTFL1A. Network analysis was carried for haplotypes identified for 70 polymorphic sites in the VVTFL1A gene excluding recombined haplotypes. Haplotypes are represented by circles with circle size proportional to haplotype frequency (circle size corresponding to haplotype numbers of 1,5 and 25 are illustrated). The haplotypes colours relate to the accessions classification according to according to structured genetic groups (Additional file 1). Black dots represent mutational steps. Colour lines represent the mutations in LD that separated the three haplogroups identified (HG). 


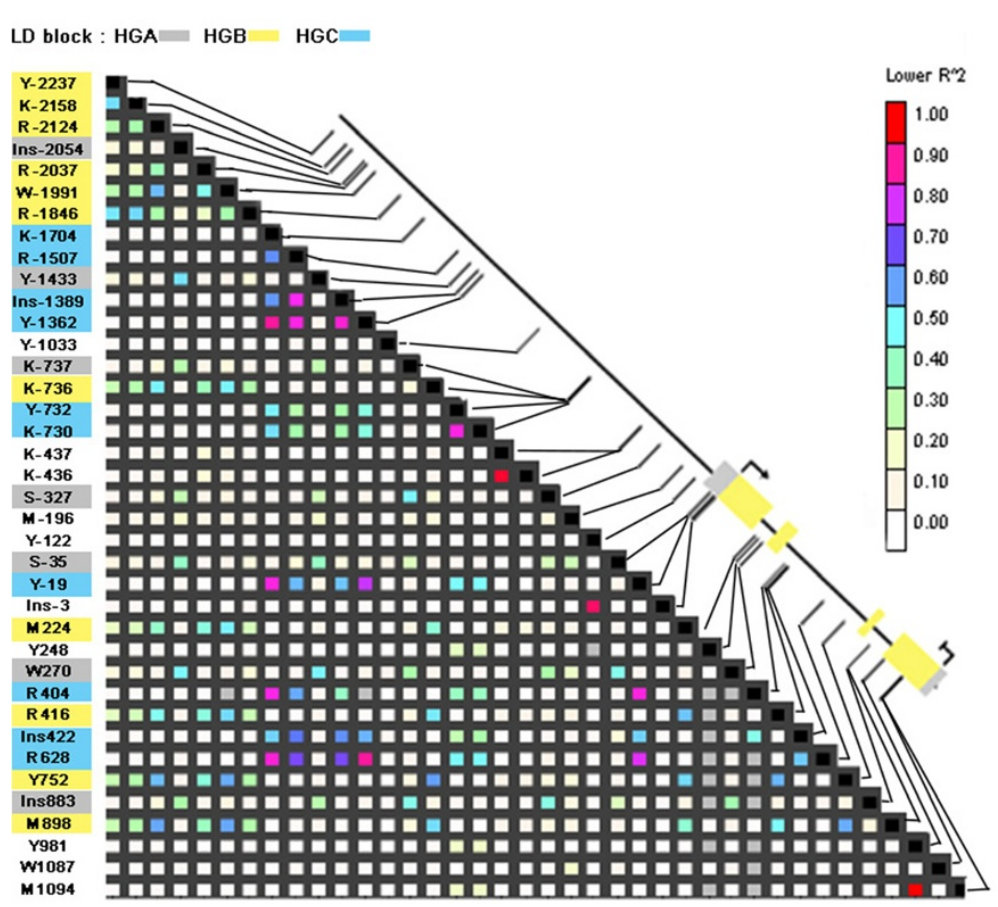

Figure 5 Linkage disequilibrium among polymorphisms in the gene VvTFL1A. LD plot based on $R^{2}$ values for SNP and INDEL with frequency $>5 \%$ were estimated according to Remington et al. [53]. The schematic representation of the VVTFL 1A locus indicates ATG and stop codon position, exon regions represented by yellow boxes and UTR by grey boxes. Polymorphism classification into three LD blocks is represented by a colour code.

Table 3 List of VvTFLIA polymorphisms showing significant association after Bonferroni correction $(<0.05)$ with flowering time, cluster width and berry weight through structured MLM tests using either R or TASSEL

\begin{tabular}{|c|c|c|c|c|c|c|c|}
\hline \multirow[b]{2}{*}{ Trait } & \multirow[b]{2}{*}{ Marker } & \multirow[b]{2}{*}{ Haplogroup } & \multicolumn{2}{|l|}{ MLM-R } & \multicolumn{3}{|c|}{ MLM-TASSEL } \\
\hline & & & $P$-value & Bonf corr $<0.05$ & $P$-value & Bonf corr $<0.05$ & R2 Marker \\
\hline \multirow[t]{3}{*}{ Flowering time } & Ins883 & HGA & 2.72E-04 & * & 2.19E-03 & & 0.104 \\
\hline & $\mathrm{K}-737$ & HGA & $1.04 \mathrm{E}-03$ & * & $6.42 \mathrm{E}-03$ & & 0.089 \\
\hline & Ins422 & $\mathrm{HGC}$ & $1.24 \mathrm{E}-03$ & * & $6.01 \mathrm{E}-03$ & & 0.089 \\
\hline \multirow[t]{8}{*}{ Berry weight } & M-196 & & 1.47E-08 & * & $2.23 \mathrm{E}-06$ & * & 0.163 \\
\hline & Ins883 & HGA & $5.76 \mathrm{E}-07$ & * & 8.40E-05 & * & 0.118 \\
\hline & S-327 & HGA & $1.33 \mathrm{E}-06$ & * & 3.06E-04 & * & 0.105 \\
\hline & K-737 & HGA & $3.54 \mathrm{E}-06$ & * & $5.83 \mathrm{E}-04$ & & 0.095 \\
\hline & S-35 & HGA & 9.17E-06 & * & 4.24E-04 & * & 0.105 \\
\hline & W270 & HGA & $1.02 \mathrm{E}-04$ & * & $2.84 \mathrm{E}-04$ & * & 0.112 \\
\hline & Ins-2054 & HGA & $1.58 \mathrm{E}-04$ & $*$ & $2.16 \mathrm{E}-03$ & & 0.074 \\
\hline & Ins422 & HGC & 2.32E-04 & * & $1.30 \mathrm{E}-02$ & & 0.059 \\
\hline \multirow[t]{4}{*}{ Cluster width } & Ins883 & $\mathrm{HGA}$ & $1.63 \mathrm{E}-05$ & * & $1.72 \mathrm{E}-04$ & * & 0.130 \\
\hline & $\mathrm{K}-737$ & HGA & $9.18 \mathrm{E}-05$ & $*$ & $1.88 \mathrm{E}-03$ & & 0.097 \\
\hline & S-327 & $\mathrm{HGB}$ & 3.34E-04 & * & 3.30E-03 & & 0.086 \\
\hline & Ins422 & $\mathrm{HGC}$ & 1.07E-03 & * & $1.34 \mathrm{E}-02$ & & 0.066 \\
\hline
\end{tabular}


phenological and cluster morphological traits that could be related with its putative biological function in grapevine. Association tests for VvTFL1A gene were run between the 38 polymorphisms showing minor allele frequency $\geq 5 \%$ and each phenotypic trait. Rare genotyping classes $(\leq 5 \%)$ were excluded from the association tests. Out of the 38 polymorphisms, only 8 presented significant associations (adjusted $P$-value $\leq 0.05$ ) using either R or TASSEL with flowering time, berry weight and cluster width (Table 3, Figure 2B).

The strongest association was found between berry weight and SNP M-196 $\left(P=1.4 \mathrm{E}^{-8}\right)$ explaining $16 \%$ of the trait variation. The highest association for flowering time and cluster width was found with Ins883 $\left(P=2.7 \mathrm{E}^{-4}\right.$, $P=1.6 \mathrm{E}^{-5}$, respectively) that explained $10 \%$ and $13 \%$ of trait variation, respectively. Interestingly, Ins 883 characteristic of HGA also associated significantly $(P \leq 0.01)$ with berry weight $\left(P=5.7 \mathrm{E}^{-7}\right)$. At a lesser extent, Ins 422 from HGC associated with the three traits explaining 9\%,6\% and $7 \%$ of flowering time, berry weight and cluster width variations, respectively.

In order to determine whether the different associations detected were only due to LD or were the result of the particular effect of each polymorphism, the multilocus mixed-model analysis was carried out. Flowering time showed the strongest associations with polymorphisms characteristic of HGA and HGC under singlelocus approaches (Table 3). In the multi-locus analysis, the best models to explain flowering time variation identified one and two polymorphisms based on optimal mBonf and EBIC criteria, respectively (Table 4). The optimal models included Ins833 from HGA specific LD block and W1087 without LD with other polymorphisms and explained up to $16 \%$ of flowering time variation. Association between W1087 and flowering time was not identified with the single-locus approach; the use of Ins883 as covariate in the model revealed W1087 association. The remaining markers, not included in the model, had minor and/or redundant effects with those ones. Similarly, the best models explaining up to $25 \%$ of berry weight variation included M-196 and Ins883 in agreement with the highest associations detected with the single-locus approach. Instead, cluster width variation showing associations with polymorphisms within the three LD blocks under single-locus approaches was only explained by polymorphism Ins 883 (HGA) after the multi-locus mixed-model analysis. The effect of polymorphisms characteristic of HGB was minor and redundant with those of Ins883. Therefore, in addition to its high association $(P \leq 0.01)$ in single-locus analyses with three traits (flowering time, cluster width and berry weight), Ins 883 was selected in the three best multi-locus models explaining the variation of those traits. Besides, Ins 883 explains alone cluster width variation. These results highlight the major influence of INDEL Ins883 in the possible role of $V v T F L 1 A$ on phenology and cluster traits.

\section{Phenotypic values related to major haplotypes}

Based on haplotype network and association results, two molecular polymorphisms (Ins883 and Ins422) were selected that discriminated the three haplogroups (HGA:

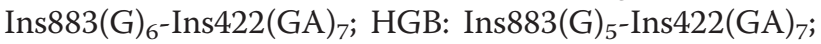
HGC: Ins883(G) $)_{5}$-Ins422(GA) $)_{8}$ ). The $(\mathrm{G})_{6}$ allele of Ins883 was associated with late flowering time, high berry weight and large cluster width (Figure 6). All haplotypes in HGA presented the $(G)_{6}$ allele, in contrast with haplotypes in HGB and HGC that contained the $(G)_{5}$ allele Regarding Ins 422 , the $(\mathrm{GA})_{8}$ allele was associated with early flowering time, low berry weight and small cluster width (Figure 6). All haplotypes carrying the $(\mathrm{GA})_{8}$ allele belonged to HGC, mainly represented by haplotype 60 , while haplotypes in HGA and HGB contained the $(\mathrm{GA})_{7}$ allele.

As other polymorphisms appeared associated with these phenotypic traits, the phenotypic values were also analysed considering the three major haplotypes 32,3 and 60 from HGA, B and C, respectively. As an average, individuals presenting at least one haplotype 32 exhibited late flowering, big berries and large cluster clearly in contrast to the phenotypic features of individuals containing at least one haplotype 3 or 60 (Figure 7). This was more obvious when homozygous individuals or heterozygous individuals for haplotypes 3 and 60

Table 4 MLMM results

\begin{tabular}{lllllllll}
\hline Trait & Forward step & mBonf $<\mathbf{0 . 0 5}$ & EBIC & Markers in the model & Gene region & Haplogroup & R2 Markers & R2 Model \\
\hline Flowering time & 1 & $8.98 \mathrm{E}-03$ & 609 & Ins883 & Intron3 & HGA & 0.11 & 0.19 \\
& 2 & $2.61 \mathrm{E}-01$ & 603 & + W1087 & Exon4 & & 0.16 & 0.25 \\
Cluster width & 1 & $5.38 \mathrm{E}-04$ & 492 & Ins883 & Intron3 & HGA & 0.13 & 0.34 \\
Berry weight & 1 & $1.26 \mathrm{E}-06$ & 431 & M-196 & Promoter & & 0.21 & 0.76 \\
& 2 & $1.49 \mathrm{E}-01$ & 412 & + Ins883 & Intron3 & HGA & 0.25 & 0.80 \\
\hline
\end{tabular}

The models presented corresponded to the optimal models, i.e., optimizing EBIC and mBonf criteria. R2 Markers = variance explained by polymorphisms in each model, R2 Model = cumulative variance explained by markers and genetic variance (structure and kinship). 

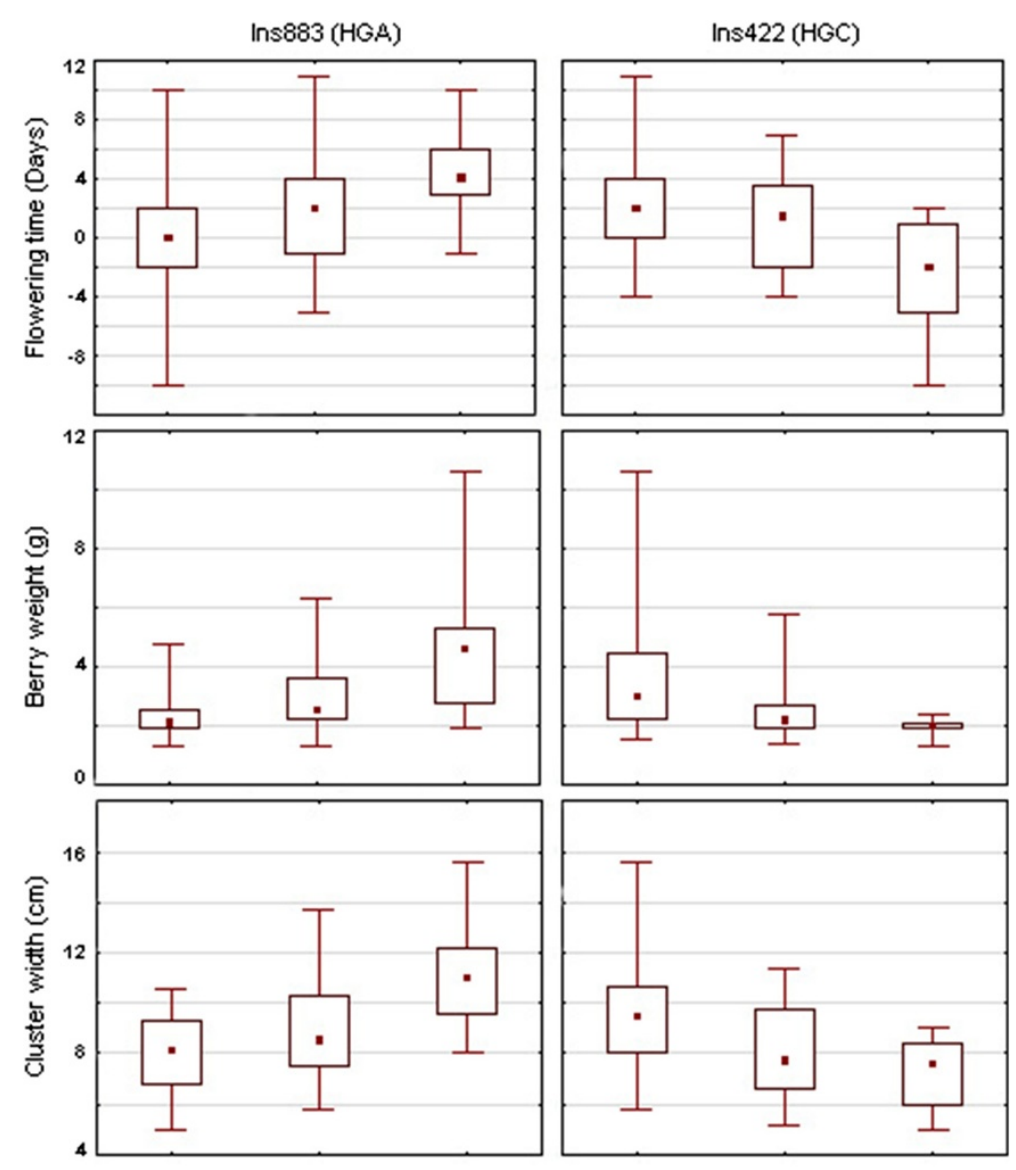

$(G)_{5} \quad(G)_{5}(G)_{6} \quad(G)_{6}$

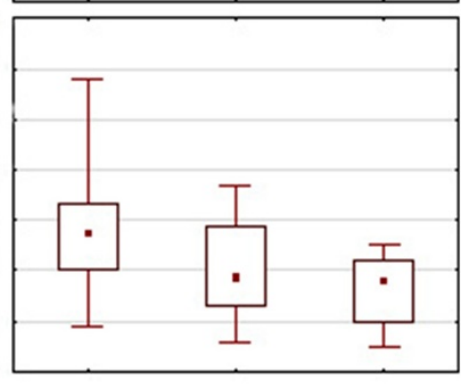

(GA) (GA) $)_{1}(G)_{6} \quad(G A)_{6}$

Figure 6 Effects of VvTFL1A INDEL Ins883 and Ins422 on flowering time, berry weight and cluster width. Box plots represent minimum and maximum (whisker), median (square dot), and 25th and 75th percentiles (box) values.

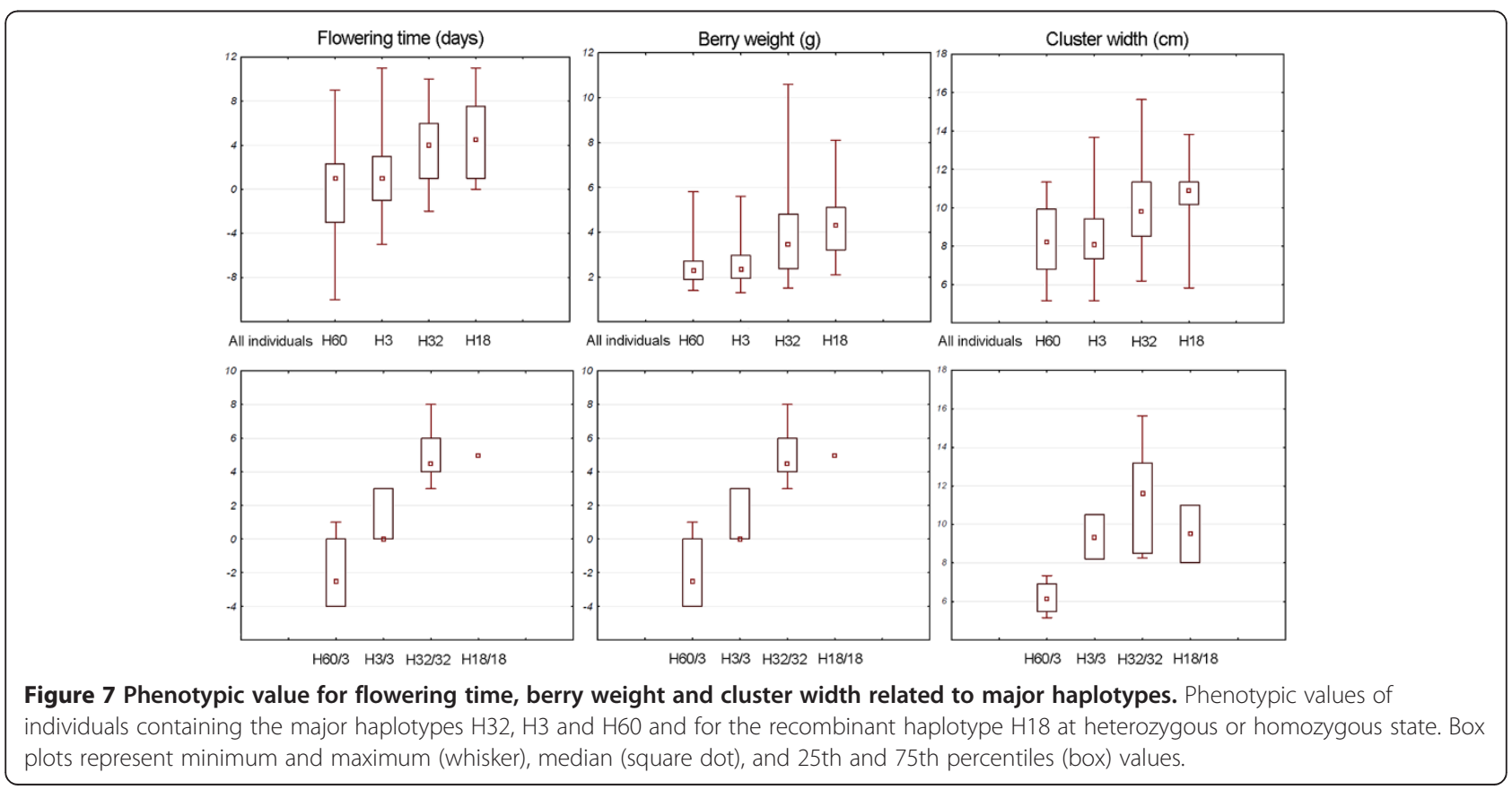


were taken into account considering the absence of homozygous individuals for haplotype 60 (Figure 7). The phenotypic value for the more frequent recombinant haplotype 18 found in Eastern table cultivars was also analysed, which presented the $(G)_{6}$ allele at the major INDEL Ins883 such as haplotypes of HGA. Phenotypic values for flowering time, berry weight and cluster width for haplotype 18 were slightly higher than those of individuals carrying haplotype 32 (Figure 7).

\section{Discussion}

Arabidopsis TFL1 plays a critical role in the specification of the inflorescence meristem and inflorescence architecture $[54,55]$. This role seems to be conserved in other plant species [56] likely through a conserved regulatory pathway [24]. In grapevine, the previous identification of misexpression of the Arabidopsis homolog VvTFL1A as the molecular cause of the reiteration of reproductive meristems (RRM) mutant [26], also supported the possible conservation of its biological function in this species in agreement with previous results [57,58]. Phenotypic characterization of the RRM plants showed that VvTFL1A overexpression was related to a delay in the time of anthesis and to an increase in the size and branching pattern of the inflorescences [26], similar to the effects of TFL1 overexpression in transgenic Arabidopsis [21]. To provide additional evidence on the involvement of VvTFL1A in natural variation for flowering time and inflorescence development and to identify nucleotide sequence polymorphisms that could be partially responsible for those traits in grapevine, a genetic diversity analysis of this gene sequence and genetic association studies with those traits were carried out.

Nucleotide variations for $V v T F L 1 A$ in the grapevine core collection analysed is relatively high with an average of one polymorphic site every 50 nucleotides. However, only five out of the 70 polymorphisms detected are located in exonic regions and only three of them result in non-synonymous amino acid substitutions. This result is in agreement with the slight negative Tajima's D values observed along VvTFL1A coding sequences and suggests that the protein structure admits few variations. Reduction in overall level of nucleotide variation was also reported for the Arabidopsis TFL1 gene when compared with other flowering genes [59]. Among the three nonsynonymous polymorphisms identified in VvTFL1A, W13, located in first exon, had a very low frequency and was not considered for the association analyses. The two other, W1087 and M1094, are located in the fourth exon in a region of the protein responsible for the functional divergence between FT and TFL1 [60]; although the substituted amino acids do not correspond to conserved residues [60] and the SNP did not associate with inflorescence related traits under single-locus models.
However, W1087 was selected by the multi-locus mixedmodel analysis to explain part of flowering time variation together with Ins883 suggesting a possible functional effect of this SNP in this trait. Regarding the 17 polymorphisms found in intron regions, two INDEL (Ins422 and Ins883) showed significant association with flowering and cluster trait variation. INDEL Ins422 is located in intron 2 and corresponds to a microsatellite sequence of GA repetitions; while INDEL Ins883 is located in intron 3 and corresponds to a $\mathrm{G}$ nucleotide repetition. The 48 remaining VvTFL1A polymorphisms identified in the core collection were located upstream of the translation start codon and included four INDEL. No traces of the Hatvine1-rrm transposon were detected in the promoter of VVTFL1A in the whole core collection which demonstrates the specificity of the insertion event causing the Carignan RRM mutant phenotype [26].

Nucleotide polymorphisms in VVTFL1A LD blocks that discriminate the three haplogroups displayed differential association with cluster traits under linear regression models. Among all traits analysed, polymorphic sites characteristic of HGA and HGC haplogroups explained part of the phenotypic variation for flowering time, berry weight and cluster width. In the same way, polymorphisms specific of HGB associated with cluster width as well as polymorphisms from HGA. These results suggest that variation at VvTFL1A has an effect on flowering time, berry weight and cluster width with different alleles having differential effects on the traits. Interestingly, both flowering time delay and cluster width increase were observed in the phenotypic characterization of the RRM somatic variant related to $V v T F L 1 A$ overexpression. Unfortunately, berry size was not measured in that study [26].

Among all the polymorphic sites tested, insertion Ins883 discriminating HGA from HGB and HGC explained alone part of flowering time, berry weight and cluster width variations. According to the multi-locus analysis, Ins833 explained up to $16 \%, 13 \%$ and $25 \%$ of flowering time, cluster width and berry weight variation in the best models, being the only polymorphism contributing to berry weight variation. INDEL occurring in functionally important regions of genes could affect gene function, through gene expression modification [61] or RNA structure alterations [62]. However, a preliminary VvTLF1A RT qPCR expression analysis carried out in young inflorescences of the cultivars of the core collection did not reveal any association between gene expression variation and the VvTFL1A polymorphisms (data not shown). Likewise, no clear correlation (Pearson's $\mathrm{r}<0.28)$ between VvTFL1A expression and phenotypic traits was identified (data not shown). Nevertheless, these negative results do not discard a possible role of this intron sequences in transcriptional or posttranscriptional processes given the difficulties in carrying out transcriptional comparisons among different genotypes with different 
flowering behaviour. Analysis of maize TFL1 homologs expression in different tissues and developmental stages showed the existence of differential transcript processing [63]. In fact, in a preliminary study, the existence of alternatively spliced RNA forms was detected for the first and the second introns of VvTFL1A (data not shown). Further research will be required to demonstrate any functional role of this alternative splicing as well as its relationship with the described VvTFL1A Ins833 polymorphism. In any case, further association analyses using larger samples and specific segregation analyses will be required to confirm the detected associations.

Together with Ins883, M-196 and W1087 without LD with other VvTFL1A polymorphisms explain part of berry weight and flowering time variation according to multi-locus analysis, respectively. In contrast to Ins883 that discriminates haplotypes of HGA from those of HGB and HGC, M-196 and W1087 corresponded to mutations differentiating haplotypes within the HGA haplogroup (Figure 4). The M-196 base change located in the proximal promoter and the W1087 non-synonymous substitution in the fourth exon of VvTFL1A might represent relevant structural modifications at the promoter and the protein sequence, respectively, likely affecting VvTFL1A function in a non-redundant way with Ins883. Moreover, in silico analysis using SIFT program (http:// sift.jcvi.org/) predicts that substitution of $\mathrm{T}$ by $\mathrm{S}$ at position 144 of the VvTFL1A sequence affects protein function with a score of 0.04 based on the alignment of 240 closely related sequences.

VvTFL1A haplotype network differentiates three haplogroups of closely related haplotypes. Each HG is represented by a high frequency haplotype, haplotypes 32 for HGA, 3 for HGB and haplotype 60 from HGC. Consistent with the results of the association analyses, individuals containing haplotype 32 of HGA, exhibited late flowering, large cluster width and larger berries. Interestingly, most of the cultivars of $\mathrm{K} 1$ and $\mathrm{K} 3$ classified to table or table/ wine uses, characterized by these phenotypic features [6], present HGA haplotypes. This relationship is also true for accessions carrying the recombinant haplotype 18 . Indeed, haplotype 18 contains Ins883 insertion present in HGA haplotypes and mostly present in Eastern table cultivars belonging to $\mathrm{K} 1$ and $\mathrm{K} 3$ genetic groups. The fact that cultivars carrying haplotype 18 display late flowering, large cluster width and larger berries supports a clear relationship between Ins883 polymorphism and the eastern table cluster characteristics. In contrast, individuals containing haplotype 60 of HGC with Ins422 insertion exhibited early flowering, shorter cluster width and smaller berries. Consistently, HGC haplotypes are enriched in Western wine grape cultivars mostly belonging to $\mathrm{K} 2$ genetic group, which are known to display those cluster and berry features [6]. Finally, HGB haplotypes do not contain Ins422 or Ins883 insertions. The phenotype of individuals containing haplotype 3 (most frequent within HGB) is similar to some extent to that of cultivars carrying haplotype 60 (HGC). Consistently with this phenotype, HGB haplotypes are mostly present in cultivars for wine use. Because no homozygous individuals were observed for haplotype 60 in the core collection, the phenotypic effect of this haplotype is supposed to be much stronger in homozygous state, which suggests that haplotype 60 , related to extreme phenology and cluster characteristics, could be less favored in cultivars in homozygous state than haplotype 3. Interestingly, partial sequencing of VvTFL1A in $20 \mathrm{~V} . v$ ssp. sylvestris plants from the Iberian Peninsula identified wild haplotypes similar to haplotype 60 and belonging to HGC (data not shown). These data could indicate a western origin for haplotypes of HGC.

\section{Conclusions}

Three major VvTFL1A haplogroups were identified in cultivated grapevines based on the presence of three main polymorphism LD blocks. These haplogroups are associated to characteristic phenotypic values for flowering time, cluster width and berry size. Phenotypic differences between $V v T F L 1 A$ haplogroups are consistent with the classification of grapevine phenotypic diversity in three different morphotypes proposed by Negrul [12] and could result from the use of different genetic pools in grapevine domestication and/or the existence of different selection pressures on the development of table and wine cultivars. Polymorphic markers identifying haplogroups can also be relevant in marker-assisted breeding programs addressing the improvement of cluster structure and berry size.

\section{Additional files}

Additional file 1: List of the 140 individuals of the core collection used in this study. Variety name, pedigrees when available, bred cultivars and classification according to origin and use are indicated. Classification of individuals according to K1, K2, K3 and admixed groups is described (see materials and methods section) as well as haplotype combination and corresponding haplogroups. [N.D. not determined].

Additional file 2: Principal component analysis of phenotypic data.

Additional file 3: Phenotypic value presented by the 140 individuals of the core collection for the 10 traits analysed in this study.

Additional file 4: Distributions of the ten phenotypic traits analysed in the core collection. Red line corresponds to the expected normal distribution.

Additional file 5: Genotype of the 140 core collection accessions for the $\mathbf{7 0}$ polymorphisms of VvTFL 1A. The standart IUB's nomenclature for nucleic acid has been used to code SNPS. For INDEL $A=$ deletion, $C=$ insertion, $M=$ heterozygous, and for triallelic microsatellites third allele has been codify as $\mathrm{T}$. [n/a $=$ not available $]$. 
Additional file 6: Sequences of the 53 haplotypes found for the VvTFL1A gene. Only polymorphic sites are indicated. Frequency and recombinant haplotypes are indicated.

\section{Competing interests}

The authors declare that they have no competing interests.

\section{Authors' contributions}

LF, PT, LT and JMM-Z conceived the study. LLC, TL, JMB, SL and PT created and characterized the core collection. LF and GB generated and characterized the sequence data. LF, LLC, JT, AFL analysed the data. LF and $J M M-Z$ wrote the paper with the input of all authors. All authors read and approved the final manuscript.

\section{Acknowledgments}

We would like to thank Dr Javier Ibanez and Dr Stéphanie Mariette for helpful discussions; Virginia Rodriguez for her assistance for DNA extraction; Dr Carlos Alonso Blanco for his helpful comments and critical reading of the manuscript and Dr Vincent Segura is acknowledged for assistance using MLMM software and critical reading of the manuscript. This work was funded by grant BIO2008-03892 and BIO2011-026229 from the MICINN and MINECO of Spain to JMM-Z. Networking activities were also funded by COST Action FA1003 "East-west Collaboration for Grapevine Diversity Exploration and Mobilization of Adaptive Traits for Breeding". JT was recipient of a fellowship from the MICINN.

\section{Author details}

${ }^{1}$ Instituto de Ciencias de la Vid y del Vino (ICW), (CSIC, Universidad de La Rioja, Gobierno de La Rioja), CCT, C/Madre de Dios 51, Logroño 26006, Spain. ${ }^{2}$ UMT Geno-Vigne ${ }^{\circledast}$ (IFV- INRA-SupAgro), 2 Place P. Viala 34060, Montpellier, Cedex 1, France. ${ }^{3}$ Bio21 Institute, Department of Genetics, University of Melbourne, 40 Flemington road, Melbourne 3010, Australia. ${ }^{4}$ INRA-SupAgro, UMR AGAP, équipe Diversité et Adaptation de la Vigne, 2 Place P. Viala, Montpellier, Cedex 1 34060, France. ${ }^{5}$ CNB-CSIC, Dpto. de Genética Molecular de Plantas, Darwin 3, Madrid 28049, Spain. ${ }^{6}$ INRA, Unité Expérimentale du Domaine de Vassal, Route de Sète, Marseillan-plage 34340, France. ${ }^{7}$ current address: INRA, UMR Biologie du Fruit et Pathologie, B.P. 81,

Villenave-d'Ornon, Cedex 33883, France.

Received: 28 March 2014 Accepted: 23 July 2014

Published: 5 August 2014

\section{References}

1. Mc Govern PE, Glusker DL, Exner LJ, Voigt MM: Neolithic resinated wine. Nature 1996, 381:480-481.

2. Levadoux L: Les population sauvage et cultivées de Vitis vinifera $\mathrm{L}$. Annales de l' Amélioration des Plantes 1956, 6:59-118.

3. Mc Govern PE: Ancient wine. The search for the origins of viniculture. Princeton, NJ: Princeton University Press; 2003

4. Aradhya MK, Dangl GS, Prins BH, Boursiquot JM, Walker MA, Meredith CP, Simon CJ: Genetic structure and differentiation in cultivated grape, Vitis vinifera L. Genet Res 2003, 81:179-192.

5. Arroyo-Garcia R, Ruiz-Garcia L, Bolling L, Ocete R, Lopez MA, Arnold C, Ergul A, Soylemezoglu G, Uzun HI, Cabello F, Ibanez J, Aradhya MK, Atanassov A, Atanassov I, Balint S, Cenis JL, Costantini L, Goris-Lavets S, Grando MS, Klein BY, McGovern PE, Merdinoglu D, Pejic I, Pelsy F, Primikirios N, Risovannaya V, Roubelakis-Angelakis KA, Snoussi H, Sotiri P, Tamhankar S, et al: Multiple origins of cultivated grapevine (Vitis vinifera L. ssp. sativa) based on chloroplast DNA polymorphisms. Mol Ecol 2006, 15:3707-3714.

6. Bacilieri R, Lacombe T, Le Cunff L, Di Vecchi-Staraz M, Laucou V, Genna B, Peros JP, This P, Boursiquot JM: Genetic structure in cultivated grapevines is linked to geography and human selection. BMC Plant Biol 2013, 13:25.

7. Emanuelli F, Lorenzi S, Grzeskowiak L, Catalano V, Stefanini M, Troggio M, Myles S, Martinez-Zapater JM, Zyprian E, Moreira FM, Grando MS: Genetic diversity and population structure assessed by SSR and SNP markers in a large germplasm collection of grape. BMC Plant Biol 2013, 13:39.

8. Myles S, Boyko AR, Owens CL, Brown PJ, Grassi F, Aradhya MK, Prins B, Reynolds A, Chia JM, Ware D, Bustamante CD, Buckler ES: Genetic structure and domestication history of the grape. Proc Natl Acad Sci U S A 2011, 108:3530-3535.
9. Myles S, Chia JM, Hurwitz B, Simon C, Zhong GY, Buckler E, Ware D: Rapid genomic characterization of the genus vitis. PLoS One 2010, 5:e8219.

10. Branas J: Viticulture. Montpellier: Paul Dehan; 1974.

11. Boursiquot JM, Dessup M, Rennes C: Distribution des principaux caractères phénologiques, agronomiques et technologiques chez Vitis vinifera L. Vitis 1995, 34:31-35.

12. Negrul AM: Origin and classification of cultured grape. In The Ampelography of the USSR. Edited by Baranov A, Kai YF, Lazarevski MA, Palibin TV, Prosmoserdov NN, Baranov A, Kai YF, Lazarevski MA, Palibin TV, Prosmoserdov NN. Moscow: Pischepromizdat; 1946:159-216.

13. Molitor D, Rothmeier M, Behr M, Fischer S, Hoffman L, Evers D: Crop cultural and chemical methods to control grey mould on grapes. Vitis 2011, 50:81-87.

14. Vail ME, Marois JJ: Grape cluster architecture and the susceptibility of berries to Botrytis cinerea. Phytopatholog 1991, 81:188-191.

15. Shavrukov YN, Dry IB, Thomas MR: Inflorescence and bunch architecture development in Vitis vinifera L. Aust J Grape Wine Res 2003, 10:116-124.

16. Tello J, Ibáñez J: Evaluation of indexes for the quantitative and objective estimation of grapevine bunch compactness. Vitis 2014, 53:9-16.

17. Bradley D, Ratcliffe O, Vincent C, Carpenter R, Coen E: Inflorescence commitment and architecture in Arabidopsis. Science 1997, 275:80-83.

18. Shannon S, Meeks-Wagner DR: A mutation in the Arabidopsis TFL1 gene affects inflorescence meristem development. Plant Cell 1991, 3:877-892.

19. Prusinkiewicz P, Erasmus Y, Lane B, Harder LD, Coen E: Evolution and development of inflorescence architectures. Science 2007, 316:1452-1456.

20. Schoentgen F, Saccoccio F, Jolles J, Bernier I, Jolles P: Complete amino acid sequence of a basic 21-kDa protein from bovine brain cytosol. Eur J Biochem 1987, 166:333-338.

21. Hanano S, Goto K: Arabidopsis TERMINAL FLOWER1 is involved in the regulation of flowering time and inflorescence development through transcriptional repression. Plant Cell 2011, 23:3172-3184.

22. Weigel D, Alvarez J, Smyth DR, Yanofsky MF, Meyerowitz EM: LEAFY controls floral meristem identity in Arabidopsis. Cell 1992, 69:843-859.

23. Parcy F, Nilsson O, Busch MA, Lee I, Weigel D: A genetic framework for floral patterning. Nature 1998, 395:561-566

24. Liu C, Teo ZW, Bi Y, Song S, Xi W, Yang X, Yin Z, Yu H: A conserved genetic pathway determines inflorescence architecture in Arabidopsis and rice. Dev Cell 2013, 24:612-622.

25. Carmona MJ, Cubas P, Calonje M, Martinez-Zapater JM: Flowering transition in grapevine (Vitis vinifera L.). Can J Bot 2007, 85:701-711.

26. Fernandez $L$, Torregrosa $L$, Segura $V$, Bouquet A, Martinez-Zapater JM: Transposon-induced gene activation as a mechanism generating cluster shape somatic variation in grapevine. Plant J 2010, 61:545-557.

27. Barnaud A, Lacombe T, Doligez A: Linkage disequilibrium in cultivated grapevine, Vitis vinifera L. Theor App/ Genet 2006, 112:708-716.

28. Lacombe T, Boursiquot JM, Laucou V, Di Vecchi-Staraz M, Peros JP, This P. Large-scale parentage analysis in an extended set of grapevine cultivars (Vitis vinifera L.). Theor App/ Genet 2013, 126:401-414.

29. Adam-Blondon AF, Roux C, Claux D, Butterlin G, Merdinoglu D, This P: Mapping 245 SSR markers on the Vitis vinifera genome: a tool for grape genetics. Theor Appl Genet 2004, 109:1017-1027.

30. Bradbury PJ, Zhang Z, Kroon DE, Casstevens TM, Ramdoss Y, Buckler ES: TASSEL: software for association mapping of complex traits in diverse samples. Bioinformatics 2007, 23:2633-2635.

31. Rozas J, Sanchez-DelBarrio JC, Messeguer X, Rozas R: DnaSP, DNA polymorphism analyses by the coalescent and other methods. Bioinformatics 2003, 19:2496-2497.

32. Nei M: Molecular Evolutionary Genetics. New York, NY: Columbia University Press; 1987.

33. Watterson GA: On the number of segregating sites in genetical models without recombination. Theor Pop Biol 1975, 7:256-276.

34. Tajima F: Statistical method for testing the neutral mutation hypothesis by DNA polymorphism. Genetics 1989, 123:585-595.

35. Thornsberry JM, Goodman MM, Doebley J, Kresovich S, Nielsen D, Buckler ES: Dwarf8 polymorphisms associate with variation in flowering time. Nat Genet 2001, 28:286-289.

36. Yu J, Pressoir G, Briggs WH, Vroh Bi I, Yamasaki M, Doebley JF, McMullen MD, Gaut BS, Nielsen DM, Holland JB, Kresovich S, Buckler ES: A unified mixed-model method for association mapping that accounts for multiple levels of relatedness. Nat Genet 2006, 38:203-208. 
37. Laucou V, Lacombe T, Dechesne F, Siret R, Bruno JP, Dessup M, Dessup T, Ortigosa P, Parra P, Roux C, Santoni S, Vares D, Peros JP, Boursiquot JM, This P. High throughput analysis of grape genetic diversity as a tool for germplasm collection management. Theor Appl Genet 2011, 122:1233-1245.

38. Pritchard JK, Stephens M, Donnely P: Inference of population structure using multilocus genotype data. Genetics 2000, 155:945-959.

39. Evanno G, Regnaut $\mathrm{S}$, Goudet J: Detecting the number of clusters of individuals using the software STRUCTURE: a simulation study. Mol Ecol 2005, 14:2611-2620.

40. Vigouroux Y, Glaubitz JC, Matsuoka Y, Goodman MM, Sanchez GJ, Doebley J: Population structure and genetic diversity of New World maize races assessed by DNA microsatellites. Am J Bot 2008, 95:1240-1253.

41. Fournier-Level A, Le Cunff L, Gomez C, Doligez A, Ageorges A, Roux C, Bertrand $Y$, Souquet JM, Cheynier V, This P: Quantitative genetic bases of anthocyanin variation in grape (Vitis vinifera L. ssp. sativa) berry: a quantitative trait locus to quantitative trait nucleotide integrated study. Genetics 2009, 183:1127-1139.

42. Kang HM, Zaitlen NA, Wade CM, Kirby A, Heckerman D, Daly MJ, Eskin E: Efficient control of population structure in model organism association mapping. Genetics 2008, 178:1709-1723.

43. Segura V, Vilhjalmsson BJ, Platt A, Korte A, Seren U, Long Q, Nordborg M: An efficient multi-locus mixed-model approach for genome-wide association studies in structured populations. Nat Genet 2012, 44:825-830.

44. Qin ZS, Niu T, Liu JS: Partition-ligation-expectation-maximization algorithm for haplotype inference with single-nucleotide polymorphisms. Am J Hum Genet 2002, 71:1242-1247.

45. Stephens M, Donnelly P: A comparison of bayesian methods for haplotype reconstruction from population genotype data. Am J Hum Genet 2003, 73:1162-1169.

46. Martin DP, Williamson C, Posada D: RDP2: recombination detection and analysis from sequence alignments. Bioinformatics 2005, 21:260-262.

47. Maynard Smith J: Analyzing the mosaic structure of genes. J Mol Evol 1992, 34:126-129.

48. Posada D, Crandall KA: Evaluation of methods for detecting recombination from DNA sequences: computer simulations. Proc Natl Acad Sci U S A 2001, 98:13757-13762.

49. Boni MF, Posada D, Feldman MW: An exact nonparametric method for inferring mosaic structure in sequence triplets. Genetics 2007, 176:1035-1047.

50. Fournier-Level A, Lacombe T, Le Cunff L, Boursiquot JM, This P: Evolution of the VvMybA gene family, the major determinant of berry colour in cultivated grapevine (Vitis vinifera L.). Heredity (Edinb) 2010, 104:351-362.

51. Bandelt HJ, Forster P, Rohl A: Median-joining networks for inferring intraspecific phylogenies. Mol Biol Evol 1999, 16:37-48.

52. Jaillon O, Aury JM, Noel B, Policriti A, Clepet C, Casagrande A, Choisne N, Aubourg S, Vitulo N, Jubin C, Vezzi A, Legeai F, Hugueney P, Dasilva C, Horner D, Mica E, Jublot D, Poulain J, Bruyère $C$, Billault A, Segurens $B$, Gouyvenoux M, Ugarte E, Cattonaro F, Anthouard V, Vico V, Del Fabbro C, Alaux M, Di Gaspero G, Dumas V, et al: The grapevine genome sequence suggests ancestral hexaploidization in major angiosperm phyla. Nature 2007, 449:463-467.

53. Remington DL, Thornsberry JM, Matsuoka Y, Wilson LM, Whitt SR, Doebley J, Kresovich S, Goodman MM, Buckler ES: Structure of linkage disequilibrium and phenotypic associations in the maize genome. Proc Natl Acad Sci U S A 2001, 98:11479-11484.

54. Jack T: Molecular and genetic mechanisms of floral control. Plant Cell 2004, 16(Suppl 1):S1-S17.

55. Ratcliffe OJ, Amaya I, Vincent CA, Rothstein S, Carpenter R, Coen ES, Bradley DJ: A common mechanism controls the life cycle and architecture of plants. Development 1998, 125:1609-1615.

56. McGarry RC, Ayre BG: Manipulating plant architecture with members of the CETS gene family. Plant Sci 2012, 188-189:71-81.

57. Boss PK, Sreekantan L, Thomas MR: A grapevine TFL1 homologue can delay flowering and alter floral development when overexpressed in heterologous species. Funct Plant Biol 2006, 33:31-41.

58. Carmona MJ, Calonje M, Martinez-Zapater JM: The FT/TFL1 gene family in grapevine. Plant Mol Biol 2007, 63:637-650.

59. Olsen KM, Womack A, Garrett AR, Suddith Jl, Purugganan MD: Contrasting evolutionary forces in the Arabidopsis thaliana floral developmental pathway. Genetics 2002, 160:1641-1650.
60. Ahn JH, Miller D, Winter VJ, Banfield MJ, Lee JH, Yoo SY, Henz SR, Brady RL, Weigel D: A divergent external loop confers antagonistic activity on floral regulators FT and TFL1. Embo J 2006, 25:605-614.

61. Warren ST, Zhang F, Licameli GR, Peters JF: The fragile $X$ site in somatic cell hybrids: an approach for molecular cloning of fragile sites. Science 1987, 237:420-423.

62. Collins FS, Drumm ML, Cole JL, Lockwood WK, Vande Woude GF, lannuzzi MC: Construction of a general human chromosome jumping library, with application to cystic fibrosis. Science 1987, 235:1046-1049.

63. Danilevskaya ON, Meng X, Hou Z, Ananiev EV, Simmons CR: A genomic and expression compendium of the expanded PEBP gene family from maize. Plant Physiol 2008, 146:250-264.

doi:10.1186/s12870-014-0209-3

Cite this article as: Fernandez et al:: Haplotype diversity of VVTFL $1 A$ gene and association with cluster traits in grapevine

(V. vinifera). BMC Plant Biology 2014 14:209.

\section{Submit your next manuscript to BioMed Central and take full advantage of:}

- Convenient online submission

- Thorough peer review

- No space constraints or color figure charges

- Immediate publication on acceptance

- Inclusion in PubMed, CAS, Scopus and Google Scholar

- Research which is freely available for redistribution 